\title{
Cervical, anal and oral HPV detection and HPV type concordance among women referred for colposcopy
}

Maria Nasioutziki ${ }^{*}$, Kimon Chatzistamatiou$^{1}$, Panagiotis-Dimitrios Loufopoulos ${ }^{2}$, Eleftherios Vavoulidis ${ }^{1}$, Nikolaos Tsampazis ${ }^{1}$, George-Chrysostomos Pratilas ${ }^{1}$, Anastasios Liberis ${ }^{1}$, Vasiliki Karpa ${ }^{1}$, Evanggelos Parcharidis ${ }^{3}$, Angelos Daniilidis ${ }^{1}$, Konstantinos Spanos ${ }^{2}$ and Konstantinos Dinas ${ }^{1}$

\begin{abstract}
Background: Infection with human papillomaviruses (HPVs) can cause benign and malignant tumours in the anogenital tract and the oropharynx both in men and women. The aim of the presented study was to investigate cervical, anal, and oral HPV-detection rates among women referred to colposcopy for abnormal Cervical Cancer $(\mathrm{CaCX})$ screening results and assess the concordance of HPV-types among these anatomical sites.

Methods: Women referred to colposcopy at a single centre due to abnormal cytology, conducted for $\mathrm{CaCx}$ screening, were subjected to cervical Liquid-based Cytology (LBC) smear testing, anal and oral sampling. Routine colposcopy consisted in multiple biopsies and/or Endocervical Curettage (ECC). HPV-detection was performed by PCR genotyping in all three anatomical sites. In high-risk (hr) HPV-DNA positive samples either from anal canal or oral cavity, anal LBC cytology and anoscopy were performed, or oral cavity examination respectively. Descriptive statistics was used for the analysis of HPV-detection rates and phi-coefficient for the determination of HPV-positivity concordance between the anatomical sites.

Results: Out of 118 referred women, hr. HPV-DNA was detected in 65 (55.1\%), 64 (54.2\%) and 3 (2.5\%) at cervix, anal canal and oral cavity respectively while low-risk HPV-DNA was detected in 14 (11.9\%) and 11 (9.3\%) at cervix and anal canal respectively. The phi-coefficient for cervix/anal canal was 0.392 for HPV16, 0.658 for HPV31, 0.758 for HPV33, -0.12 for HPV45, 0.415 for HPV52 and 0.473 for HPV58. All values were statistically significant $(p<0.001)$.
\end{abstract}

Conclusions: The results suggest that most HPV-types, high-risk and low-risk, detected in the cervix of women with prevalent cervical dysplasia, correlate with the ones detected in their anal canal. This particularly applies for the HPV-types included in the nonavalent HPV-vaccine (HPVs 6/11/16/18/31/33/45/52/58).

Keywords: Anal, cervical, oral HPV concordance, Anal HPV-detection, Cervical HPV-detection, Human papilloma virus, Oral HPV-detection

\footnotetext{
* Correspondence: mnasioutziki@auth.gr

${ }^{1}$ 2nd Obstetrics \& Gynaecology Department, Molecular \& Morphological

Clinical Cytopathology Laboratory, Hippokration General Hospital, Medical

Faculty, School of Health Sciences, Aristotle University of Thessaloniki,

Thessaloniki, Greece

Full list of author information is available at the end of the article
}

(c) The Author(s). 2020 Open Access This article is licensed under a Creative Commons Attribution 4.0 International License, which permits use, sharing, adaptation, distribution and reproduction in any medium or format, as long as you give appropriate credit to the original author(s) and the source, provide a link to the Creative Commons licence, and indicate if changes were made. The images or other third party material in this article are included in the article's Creative Commons licence, unless indicated otherwise in a credit line to the material. If material is not included in the article's Creative Commons licence and your intended use is not permitted by statutory regulation or exceeds the permitted use, you will need to obtain permission directly from the copyright holder. To view a copy of this licence, visit http://creativecommons.org/licenses/by/4.0/ The Creative Commons Public Domain Dedication waiver (http://creativecommons.org/publicdomain/zero/1.0/) applies to the data made available in this article, unless otherwise stated in a credit line to the data. 


\section{Background}

Persistent infection with high-risk human papillomaviruses (HPVs) is necessary, but not sufficient, for the development of Cervical Cancer $(\mathrm{CaCx})$ [1-3]. HPV has been detected in other anatomical sites like the anus and the oral cavity and has been associated to some extent to anal and oropharyngeal cancer respectively [4-7].

Anal HPV-related cancer is strongly associated with the immunosuppression secondary to HIV-infection and associated with a history of anal-receptive intercourse; however, autoinoculation of vulvar warts to the perianal skin can occur. Clinically, anal HPVinfection can be either asymptomatic or present as benign warts (condylomata acuminata), dysplastic lesions (anal intraepithelial neoplasia-AIN), or a combination of both [8, 9].

Anal HPV-prevalence is higher in men who have sex with men (MSM) (58.8\%), for any HPV-type, whereas it is $30.7 \%$ for women [10]. Moreover, it has been reported that anal HPV-infection is more common in men or women who already have a genital $\mathrm{HPV}$-infection suggesting HPV-type concordance in genitalia and anus [11-14].

Less is known concerning oral HPV-infection, its prevalence and its implications including the involvement of HPV in oropharyngeal carcinogenesis [7, 15]. $\mathrm{HPV}$-prevalence in the oral cavity of women is $4.4 \%$, similar to that of men $(4.6 \%)$, however it has been reported to be higher for high-risk (hr) groups [16]. Also, in a systematic review of studies reporting on $\mathrm{HPV}$-detection rates in oral carcinomas and potentially malignant oral-disorders compared with healthy controls, it was shown that pooled HPV-DNA detection rate was higher in case of the former compared to controls [17].

Prophylactic HPV-vaccines have been implemented in the national vaccination programs of many countries for the primary prevention of $\mathrm{CaCx}$ and other HPVassociated diseases [18]. Bivalent- (for HPVs 16/18), quadrivalent- (for HPVs 6/11/16/18) and, nonavalentvaccines (for HPVs 6/11/16/18/31/33/45/52/58) are considered effective and able to reduce most HPV-related cancers [19].

Women who already have a cervical HPV-infection and especially women who have a precancerous cervical intraepithelial lesion (CIN) are considered to be susceptible to HPV-infections in other anatomical sites [20]. To investigate cervical/anal/oral HPVdetection rates among such a group of women, as well as to assess the concordance of different HPVtypes among these anatomical sites, we conducted the presented analysis on women attending a colposcopy clinic who, most likely, have already a cervical HPVinfection, either transient or productive.

\section{Materials \& methods}

\section{Study setting, participants \& sampling}

The presented analysis was conducted on samples collected from 118 women referred to the Colposcopy/Cervical Pathology Clinic of the 2nd Department of Obstetrics/Gynaecology (Hippokration Hospital, Medical Faculty Aristotle University of Thessaloniki (AUTh), Greece) for either an abnormal Pap-test screening result or for follow-up testing after surgical treatment for highgrade CIN between January 2015 and November 2016. Exclusion criteria had been pregnancy, prior total hysterectomy due to various reasons, and prior chemoradiation treatment. All women with anal hr-HPV positivity where referred to the Anal/Colorectal Clinic of the 1st Department of General Surgery, Medical Faculty AUTh, for anoscopy. Women with oral hr-HPV positivity were referred for oral examination to the Stomatology Clinic, School of Dentistry, Faculty of Health Sciences AUTh.

Each woman was subjected to cervical/anal/oral sampling. All samples were processed at the Molecular Cytopathology Laboratory of the 2nd Department of Obstetrics/Gynaecology. Ectocervical and endocervical sampling was done using a plastic Ayre's Spatula and a Cytobrush $^{\oplus}$ (CooperSurgical, USA) respectively, and anal sampling was done using the Anex ${ }^{\ominus}$ Brush (Rovers Medical Devices, Netherlands). After collection each device was directly immersed in a vial containing Preserv$\mathrm{Cyt}^{\odot}$ collection fluid (Hologic, USA), according to manufacturer's instructions. Oral samples were collected by an oral rinse with $15 \mathrm{~mL}$ Listerine $^{\oplus}$ for $30 \mathrm{~s}$ [21, 22] in sterile vials. All samples were kept between 2 and $8{ }^{\circ} \mathrm{C}$, for up to 2 days prior to testing.

\section{Cytology testing}

Cytology testing was performed on cervical/anal samples using Liquid-Based Cytology (LBC) (ThinPrep ${ }^{\oplus}$, Hologic, USA), prior to molecular testing. Cytology results were classified according to Bethesda 2014 classification [23]. ASCUS or worse (ASCUS+) results for cervical or anal samples were considered positive and required further action. Cervical cytology is routinely performed on women referred to the Colposcopy Clinic whereas anal cytology was performed in conjunction with HPV-DNA testing to assess the need for anoscopy referral (although in our study all anal hr-HPV positive women were referred).

\section{HPV DNA genotyping}

DNA extraction/purification was performed using CLART-HPV2 Extraction/Purification kit (Genomica, Spain). CLART-HPV2 detect infections and coinfections of 35 most clinically hr- (hr) and low-risk (lr) HPV-types (6/11/16/18/26/31/33/35/39/40/42/43/44/45/51/52/53/ 
54/56/58/59/61/62/66/68/70/71/72/73/81/82/83/84/85/

89). Protocol was carried out according to manufacturer's instructions. One $\mathrm{ml}$ of PreservCyt solution was used for HPV-DNA extraction with purifying columns and $5 \mu \mathrm{l}$ of that was used for PCR-Amplification. Prior to visualization, PCR-products were denaturated at 95 ${ }^{\circ} \mathrm{C}$ for $10 \mathrm{~min}$. Visualization was performed using $5 \mu \mathrm{l}$ denaturated product on CLART-microarray. Analysis and interpretation of results was automatically performed by GENOMICA's reader $\left(\mathrm{CAR}^{\oplus}\right)$.

\section{Colposcopy and histological examination}

Colposcopic evaluation was performed according to 2011 colposcopic terminology of International Federation for Cervical Pathology and Colposcopy [24]. Routine colposcopic examination consisted in multiple biopsies and/or Endocervical Curettage (ECC) (in case of a type-2 or type-3 transformation zone). Histology results could be within normal limits, Low-grade Squamous Intraepithelial Lesion (LSIL), High-grade Squamous Intraepithelial Lesion (HSIL) or cancer, according to the Lower Anogenital Squamous Terminology (LAST) [25]. Histology examination was conducted by pathologists, at Histopathology Department Hippokration Hospital, Thessaloniki, Greece. Pathological findings (SIL of any degree) were reassessed by an independent specialized pathologist and a third pathologist in case of disagreement.

\section{Anoscopy}

High-resolution anoscopy (HRA) was performed at the Anal/Colorectal Outpatient Clinic of the 1st Department of General Surgery, Papageorgiou Hospital, AUTh, Thessaloniki, Greece. An anoscope was inserted and a colposcope was used to examine the squamocolumnar junction, the anal canal including the transformation zone and the perianal skin in a systematic manner. After examination with acetic acid (3\% or $5 \%$ ), and subsequent application of Lugol's iodine solution, a decision was made regarding the anoscopic impression, which could be either within normal limits, or indicative of a LSIL, HSIL or cancer. In case of an abnormal anoscopic impression a biopsy was taken [26]. If HRA was not available, simple anoscopy was performed (providing less information regarding lesion identification and characterization). Prior to anoscopy, anal inspection and digital rectal examination was performed in all patients.

\section{Oral examination}

Oral visualization was conducted using an adequate light source in a systematic way. All mucosal surfaces were examined and lesions were recorded on a diagram. The lips were inspected first, followed consecutively by the labial mucosa, buccal mucosa, floor of the mouth, ventrum of the tongue, dorsal surface of the tongue, hard and soft palates, gingivae and teeth [27].

\section{Statistical analysis}

The main purpose of the analysis was to assess the concordance of different HPV-types among different anatomical sites in women. Phi-coefficient was used to determine HPV positivity concordance between cervical/ anal, cervical/oral, anal/oral and was calculated for each HPV-type or HPV-types group concerning these anatomical site pairs. The HPV-type groups were hr-HPV, lr-HPV and the nonavalent HPV vaccine types group (HPVs 6/11/16/18/31/33/45/52/58). Phi-coefficient can range from -1 (strong negative correlation) to +1 (strong positive correlation). Values near zero indicate no correlation. For each phi-value calculated we report the respective $p$-value. The level of significance was set to 0.05 .

Smoking habits were assessed by Smoking Intensity Index (SII), a new variable created as below: Number (cigarette/day) $\times 365 \times$ Number (years) $\div 1000$ [28]

All analyses were performed using statistical software SPSS Statistics 22.0.

\section{Results \\ Demographics}

The age of the recruited women ranged from 21 to 61 years (mean age 38.6 years). Table 1 shows demographic characteristics. Of the women recruited $50.8 \%$ reported higher education and $41.5 \%$ had no children. Most of them were of reproductive age since only $14.4 \%$ reported being in menopause. Combined oral contraceptive use was reported by $8.5 \%$ whereas $48.3 \%$ reported no contraceptive method. Moreover, $57.6 \%$ reported being current smokers and $6.8 \%$ reported being former smokers (meaning they had stopped smoking at least 1 year prior to recruitment). Among current smokers $45.5 \%$ were light-smokers $\quad(\mathrm{SII}<50), 20.6 \%$ were medium- (SII 50-100) and 33.9\% were heavy-smokers $(\mathrm{SII}>100)$. Most of them (63.6\%) reported more than four sexual partners and mean age of first sexual intercourse was 18.4 years (range: 14 to 35 ).

\section{HPV-prevalence}

As expected, due to the characteristics of the referral population in this study, cervical HPV-prevalence was high. In particular, hr-HPV prevalence was $55.1 \%$ (Table 2). Among hr-HPVs the most common was HPV16 (22.0\%), followed by HPV31 (13.6\%), HPVs 51/ 52 (each 7.6\%), HPVs 33/53 (each 5.9\%), and HPV58 (5.1\%). The remaining hr-HPVs presented prevalence below 2.5\%. Regarding lr-HPVs, the overall prevalence was $11.9 \%$. Among lr-HPVs, the most commonly detected type was HPV42 (5.9\%), followed by HPV61 
Table 1 Demographic characteristics of the study population

\begin{tabular}{|c|c|}
\hline Demographic characteristic & $N=118$ \\
\hline \multicolumn{2}{|l|}{ Age (years) } \\
\hline Mean (sd) & $38.6(10.2)$ \\
\hline Median (range) & $37(21-61)$ \\
\hline \multicolumn{2}{|l|}{ Educational level } \\
\hline 6 y (primary) & $11(9.3 \%)$ \\
\hline 12 y (secondary) & $38(32.2 \%)$ \\
\hline Technological institute & $29(24.6 \%)$ \\
\hline University & $26(22 \%)$ \\
\hline Post-grad & $5(4.2 \%)$ \\
\hline \multicolumn{2}{|l|}{ Children } \\
\hline No & 49 (41.5\%) \\
\hline 1 & $22(18.6 \%)$ \\
\hline 2 & $38(32.2 \%)$ \\
\hline 3 & $4(3.4 \%)$ \\
\hline 4 & $4(3.4 \%)$ \\
\hline \multicolumn{2}{|l|}{ Menopause } \\
\hline No & $101(85.6 \%)$ \\
\hline Yes & $17(14.4 \%)$ \\
\hline \multicolumn{2}{|l|}{ Contraception } \\
\hline No & $57(48.3 \%)$ \\
\hline COC & $10(8.5 \%)$ \\
\hline IUD & $3(2.5 \%)$ \\
\hline Male condom & $38(32.2 \%)$ \\
\hline Interrupted intercourse & $5(4.2 \%)$ \\
\hline \multicolumn{2}{|l|}{ HPV vaccination } \\
\hline No & $87(73.7 \%$ \\
\hline Quadrivalent & $14(11.9 \%)$ \\
\hline Bivalent & $4(3.4 \%)$ \\
\hline \multicolumn{2}{|l|}{ Smoking history } \\
\hline No & $32(27.1 \%)$ \\
\hline Yes & $68(57.6 \%)$ \\
\hline Ex-smoker & $8(6.8 \%)$ \\
\hline \multicolumn{2}{|l|}{ SII } \\
\hline$<50$ & $31(27.1 \%)$ \\
\hline $50-100$ & $14(11.9 \%)$ \\
\hline$>100$ & $23(19.5 \%)$ \\
\hline \multicolumn{2}{|l|}{ Number of sexual partners } \\
\hline 1 & $10(8.5 \%)$ \\
\hline 2 & $10(8.5 \%)$ \\
\hline 3 & 19 (16.1\%) \\
\hline$\geq 4$ & $75(63.6 \%)$ \\
\hline \multicolumn{2}{|l|}{ Age of first sexual intercourse } \\
\hline Mean (sd) & $18.4(2.9 \%)$ \\
\hline Median (range) & $18.0(14-35)$ \\
\hline
\end{tabular}

COC combined oral contraceptives, IUD intrauterine device, SII smoking intensity index
Table 2 Cervical, anal and oral HPV prevalence for the study population (percentages refer to the total of each age group)

\begin{tabular}{|c|c|c|c|}
\hline & $\begin{array}{l}\text { Cervical }[n=118 \\
(100.0 \%)]\end{array}$ & $\begin{array}{l}\text { Anal }[n=118 \\
(100.0 \%)]\end{array}$ & $\begin{array}{l}\text { Oral }[n=118 \\
(100.0 \%)]\end{array}$ \\
\hline HRHPV & 65 (55.1\%) & 64 (54.2\%) & $3(2.5 \%)$ \\
\hline LRHPV & $14(11.9 \%)$ & 11 (9.3\%) & $0(0.0 \%)$ \\
\hline $\mathrm{HR}+\mathrm{LRHPV}$ & 9 (7.6\%) & 23 (19.5\%) & $0(0.0 \%)$ \\
\hline HPV16/18 & 26 (22.0\%) & 16 (13.5\%) & $2(1.7 \%)$ \\
\hline HRHPV16 & $26(22.0 \%)$ & 11 (9.3\%) & $2(1.7 \%)$ \\
\hline HRHPV18 & 0 (0.0\%) & $5(4.2 \%)$ & $0(0.0 \%)$ \\
\hline HRHPV31 & 16 (13.6\%) & 18 (15.3\%) & $0(0.0 \%)$ \\
\hline HRHPV33 & 7 (5.9\%) & $6(5.1 \%)$ & $0(0.0 \%)$ \\
\hline HRHPV35 & $3(2.5 \%)$ & $3(2.5 \%)$ & $0(0.0 \%)$ \\
\hline HRHPV39 & $2(1.7 \%)$ & $0(0.0 \%)$ & $0(0.0 \%)$ \\
\hline HRHPV45 & $2(1.7 \%)$ & 1 (0.8\%) & $0(0.0 \%)$ \\
\hline HRHPV51 & 9 (7.6\%) & $12(10.2 \%)$ & $0(0.0 \%)$ \\
\hline HRHPV52 & 9 (7.6\%) & $5(4.2 \%)$ & $0(0.0 \%)$ \\
\hline HRHPV53 & 7 (5.9\%) & 20 (16.9\%) & $1(0.8 \%)$ \\
\hline HRHPV56 & $2(1.7 \%)$ & $1(0.8 \%)$ & $0(0.0 \%)$ \\
\hline HRHPV58 & $6(5.1 \%)$ & $6(5.1 \%)$ & $0(0.0 \%)$ \\
\hline HRHPV59 & $2(1.7 \%)$ & 4 (3.4\%) & $0(0.0 \%)$ \\
\hline HRHPV66 & $1(0.8 \%)$ & $8(6.8 \%)$ & $0(0.0 \%)$ \\
\hline HRHPV68 & $0(0.0 \%)$ & $0(0.0 \%)$ & $0(0.0 \%)$ \\
\hline HRHPV70 & $0(0.0 \%)$ & 7 (5.9\%) & $0(0.0 \%)$ \\
\hline HRHPV73 & $0(0.0 \%)$ & $1(0.8 \%)$ & $0(0.0 \%)$ \\
\hline HRHPV82 & $2(1.7 \%)$ & - & - \\
\hline LRHPV6 & 4 (3.4\%) & $10(8.5 \%)$ & 0 (0.0\%) \\
\hline LRHPV11 & $1(0.8 \%)$ & $1(0.8 \%)$ & $0(0.0 \%)$ \\
\hline LRHPV40 & $1(0.8 \%)$ & 4 (3.4\%) & $0(0.0 \%)$ \\
\hline LRHPV42 & 7 (5.9\%) & 5 (4.2\%) & $0(0.0 \%)$ \\
\hline LRHPV44 & 0 (0.0\%) & $2(1.7 \%)$ & $0(0.0 \%)$ \\
\hline LRHPV54 & $2(1.7 \%)$ & $2(1.7 \%)$ & $0(0.0 \%)$ \\
\hline LRHPV61 & $5(4.2 \%)$ & $5(4.2 \%)$ & $0(0.0 \%)$ \\
\hline LRHPV62 & $1(0.8 \%)$ & $3(2.5 \%)$ & $0(0.0 \%)$ \\
\hline LRHPV65 & 0 (0.0\%) & 0 (0.0\%) & $0(0.0 \%)$ \\
\hline LRHPV71 & $0(0.0 \%)$ & $1(0.8 \%)$ & 0 (0.0\%) \\
\hline LRHPV81 & $3(2.5 \%)$ & $5(4.2 \%)$ & $0(0.0 \%)$ \\
\hline LRHPV83 & $0(0.0 \%)$ & $1(0.8 \%)$ & $0(0.0 \%)$ \\
\hline LRHPV84 & $1(0.8 \%)$ & 3 (2.5\%) & $0(0.0 \%)$ \\
\hline
\end{tabular}

(4.2\%) with the rest lr-HPVs being less than $3.4 \%$ of the cases.

Anal HPV-prevalence presented similar trend to the cervical one with minor differences. The overall anal hrHPV prevalence was $54.2 \%$. The most common hr-HPV type was HPV53 (16.9\%), followed by HPV31 (15.3\%), 
HPV51 (10.2\%), HPV16 (9.3\%), HPV66 (6.8\%), HPV70 (5.9\%), HPVs 33/58 (each 5.1\%). Remaining hr-HPVs presented prevalence below 4.2\%. Lr-HPV-types were detected in $9.3 \%$ of the cases; the most common lr-HPV was HPV6 (8.5\%), followed by HPVs 42/61/81 (4.2\% each), HPV40 (3.4\%). The prevalence of the remaining lr-HPVs was less than $2.5 \%$ for each. Out of the 64 women recruited for the current analysis positive for hrHPV types and negative for intraepithelial lesion or malignancy (NILM) (42.2\%) or LSIL (57.8\%) anal cytology, only 15 women underwent anoscopy (despite their referral) with no pathological or suspicious lesions detected.

Oral HPV was detected much less frequently than cervical and anal. The overall hr-HPV and lr-HPV prevalence was 2.5 and $0.0 \%$ respectively. The only hr-HPV types detected were HPV16 (1.7\%) and HPV53 (0.8\%). No lesions were detected in the oral cavity of the women referred to oral examination.

A hr-HPV and lr-HPV co-infection was documented in 7.6, 19.5 and $0.0 \%$ concerning cervical/anal/oral samples respectively (Table 2 ). The prevalence of at least one of the nine HPV-types included in nonavalent HPV vaccine was $47.5,44.1$, and $1.7 \%$ for cervix/anus/oral cavity respectively (Table 3 ). The prevalence of these types fluctuated with age, being highest for age group 36-40 (75.0\% cervical, $70.0 \%$ anal, $5.0 \%$ oral samples), lowest for women aged $46-50$ (30.0\% cervical samples) and below 25 and 51-55 (14.1\% anal samples). A similar trend was observed for hr-HPVs concerning different age groups. Briefly, cervical hr-HPV detection was highest for women aged 36-40 (80.0\%) and lowest for women 46-50 (30.0\%), anal hr-HPV was highest for women 26-30 (76.9\%) and lowest for women below 25 (28.6\%). Low-risk types are more commonly detected in the cervix below age 25 compared to older age $(28.6 \%$ vs $23.1 \%$ or less), however, concerning the anal canal, it seems that younger women are less likely to have lrHPV infection compared to older ones $(21.4 \%$ vs 21.7 at least) (Table 3).

\section{HPV-detection concordance among different anatomical sites}

Most of HPV-types detected in cervical samples were detected also in anal samples, and for the majority of them there has been a statistically significant correlation. The phi-coefficient, regarding the cervical/ anal anatomical site pair, for hr-HPVs was 0.402 $(p<0.001)$. For cervical/oral and anal/oral phicoefficient values were -0.071 and 0.04 with $p$-values 0.443 and 0.662 respectively, indicating no correlation for the detection of these HPV-types in cervix or anus compared to oral cavity. HPV16-detection yielded similar results. Phi-coefficient values for this type were $0.392 \quad(p<0.001), 0.088 \quad(p=0.341)$ and $-0.042(p=0.646)$ for cervix compared to anus or oral cavity and for anus compared to oral cavity respectively.

Another HPV-type which yielded correlation results for the three anatomical sites was HPV53. For the cervical/anal pair phi-coefficient was $0.365(p<0.001)$, for cervical/oral $-0.023(p=0.8)$, and for anal/oral $-0.041 \quad(p=0.658)$. All remaining hr-HPV types yielded results only for the cervical/anal anatomical site pair. The strongest correlations, with a phicoefficient above 0.7 were noted for HPV33 (phi $=$ 0.758, $p<0.001$ ), HPV35 (phi $=1.0, p<0.001$ ), HPV51 (phi $=0.748, p<0.001$ ), and HPV56 (phi $=0.704, p<$ 0.001 ). Regarding the nonavalent-vaccine HPVs, correlation was significant for the cervical/anal samples (phi $=0.353, \quad p<0.001$ ), and cervical/oral samples (phi $=0.007, p=0.942)$ (Table 4).

Low-risk HPV-types were positively correlated among cervical and anal samples (phi $=0.443, p<$ 0.001 ). Specifically, the strongest correlation was reported for HPV11 (phi $=1.0, p<0.001$ ), no correlation was reported for HPVs 62 (phi $=-0.015, p=$ 0.871 ) and 84 (phi $=-0.015, p=0.871)$. The rest lrHPVs presented weak $(0.3<\mathrm{phi}<0.7)$ correlations (Table 4).

Table 3 HPV type prevalence according to age group and anatomical site

\begin{tabular}{llllllllll}
\hline & $<25(\%)^{*}$ & $26-30(\%)^{*}$ & $31-35(\%)^{*}$ & $36-40(\%)^{*}$ & $41-45(\%)^{*}$ & $46-50(\%)^{*}$ & $51-55(\%)^{*}$ & $>56(\%)^{*}$ & Total $(\%)$ \\
\hline HRHPV (cervical) & 64.3 & 61.5 & 45.5 & 80.0 & 52.2 & 30 & 42.9 & 44.4 & 55.1 \\
LRHPV (cervical) & 28.6 & 23.1 & 18.2 & 15.0 & 21.7 & 10.0 & 14.3 & 22.2 & 19.5 \\
HRHPV (anal) & 28.6 & 76.9 & 50.0 & 75.0 & 52.2 & 50.0 & 57.1 & 33.3 & 54.2 \\
LRHPV (anal) & 21.4 & 46.2 & 27.3 & 30.0 & 21.7 & 30.0 & 28.6 & 33.3 & 28.8 \\
HRHPV (oral) & 0.0 & 0.0 & 0.0 & 5.0 & 8.7 & 0.0 & 0.0 & 0.0 & 2.5 \\
LRHPV (oral) & 0.0 & 0.0 & 0.0 & 0.0 & 0.0 & 0.0 & 0.0 & 0.0 & 0.0 \\
9HPV (cervical) & 42.9 & 46.2 & 40.9 & 75.0 & 47.8 & 30.0 & 42.9 & 33.3 & 47.5 \\
9HPV (anal) & 14.3 & 69.2 & 36.4 & 70.0 & 52.2 & 40.0 & 14.3 & 22.2 & 44.1 \\
9HPV (oral) & 0.0 & 0.0 & 0.0 & 5.0 & 4.3 & 0.0 & 0.0 & 0.0 & 1.7 \\
\hline
\end{tabular}

HRHPV high-risk human papillomavirus, LRHPV low-risk human papillomavirus, 9HPV human papillomaviruses targeted by the nonavalent HPV vaccine

*Percentages refer to the total of each age group 
Table 4 Phi coefficient regarding hr- \& Ir-HPV DNA detection among different anatomical sites

\begin{tabular}{|c|c|c|c|}
\hline & $\begin{array}{l}\text { Cervical/anal } \\
\text { Phi }(95 \% \mathrm{Cl}, \mathrm{p})\end{array}$ & $\begin{array}{l}\text { Cervical/oral } \\
\text { Phi }(p)\end{array}$ & $\begin{array}{l}\text { Anal/oral } \\
\text { Phi (p) }\end{array}$ \\
\hline HRHPV & $0.402(<0.001)$ & $-0.071(0.443)$ & $0.04(0.662)$ \\
\hline LRHPV & $0.443(<0.001)$ & - & \\
\hline HRHPV16 & $0.392(<0.001)$ & $0.088(0.341)$ & $-0.042(0.646)$ \\
\hline HRHPV18 & - & - & - \\
\hline HRHPV31 & $0.658(<0.001)$ & - & - \\
\hline HRHPV33 & $0.758(<0.001)$ & - & - \\
\hline HRHPV35 & $1.0(<0.001)$ & - & - \\
\hline HRHPV39 & - & - & - \\
\hline HRHPV45 & $-0.12(0.895)$ & - & - \\
\hline HRHPV51 & $0.748(<0.001)$ & - & - \\
\hline HRHPV52 & $0.415(<0.001)$ & - & - \\
\hline HRHPV53 & $0.365(<0.001)$ & $-0.023(0.8)$ & $-0.041(0.658)$ \\
\hline HRHPV56 & $0.704(<0.001)$ & - & - \\
\hline HRHPV58 & $0.473(<0.001)$ & - & - \\
\hline HRHPV59 & $0.338(<0.001)$ & - & - \\
\hline HRHPV66 & $0.368(<0.001)$ & - & - \\
\hline HRHPV68 & - & - & - \\
\hline HRHPV70 & - & - & - \\
\hline HRHPV73 & - & - & - \\
\hline HRHPV82 & - & - & - \\
\hline LRHPV6 & $0.447(<0.001)$ & - & - \\
\hline LRHPV11 & $1.0(<0.001)$ & - & - \\
\hline LRHPV40 & $0.494(<0.001)$ & - & - \\
\hline LRHPV42 & $0.481(<0.001)$ & - & - \\
\hline LRHPV44 & - & - & - \\
\hline LRHPV54 & - & - & - \\
\hline LRHPV61 & $0.373(<0.001)$ & - & - \\
\hline LRHPV62 & $-0.015(0.871)$ & - & - \\
\hline LRHPV65 & - & - & - \\
\hline LRHPV71 & - & - & - \\
\hline LRHPV81 & $0.501(<0.001)$ & - & - \\
\hline LRHPV83 & - & - & - \\
\hline LRHPV84 & $-0.015(0.871)$ & - & - \\
\hline $\begin{array}{l}\text { Nonavalent HPV } \\
\text { vaccine types }\end{array}$ & $0.353(<0.001)$ & $0.007(0.942)$ & \\
\hline
\end{tabular}

\section{Discussion}

In the recent years, there has been an increasing interest in HPV-infection concerning anatomical areas other than the cervix. It has been hypothesized that HPV could be a carcinogenic factor for anal as well as oropharyngeal cancer, apart from cervical, for which it is known to be a necessary condition, since hr-HPV is detected in 99.7\% of all cervical cancer cases worldwide [1].
Anal cancer is the second most related to HPV cancer after cervical, since HPV DNA has been reported to be present in $88 \%$ of anal cancer cases, with HPV16 being the predominant type $[6,29]$. Moreover, the incidence of anal cancer has been increasing during the past decades particularly for high-risk groups, both for males and females [30].

Epidemiological features of anal cancer share similarities with the ones for anal HPV-infection. MSM consist a high-risk group for both conditions and for this group HPV-prevalence is about $58.8 \%$ for any HPV-type, $29.1 \%$ for hr-HPVs and $33.3 \%$ for lr-HPVs. Concerning the most common and important HPV-type, HPV16, its prevalence for MSM is $11.4 \%$. As far as men who have sex with women are concerned, anal HPV-prevalence is 14.2\% for any HPV, 5.5\% for hr-HPVs, 9.0\% for lr-HPVs and $1.6 \%$ for HPV16, whereas regarding women, the respective values are $30.7 \%, 13.1 \%, 17.1 \%$, and $4.3 \%$ [10]. Therefore, it seems that women from the general population, are more likely to have an anal HPV-infection than men (with the exception of MSM). Also, women seem to be affected more than men by anal cancer which presents $50 \%$ higher incidence in females than males [31-33].

Women with HPV-related pathology of the genitalia, namely the vulva, the vagina and particularly the cervix tend to have anal HPV-infections more frequently. Anal HPV-prevalence for these women ranges from 23\% to $86 \%$ compared to $5-22 \%$ for women with no known HPV-related pathology as indicated by a systematic review on female anal HPV-infection [12]. Particularly, regarding women with cervical dysplasia or with history of cervical cancer, there are studies indicating a high anal HPV-prevalence compared to women without any [34-39]. In our analysis of a colposcopy referral population, we found an anal HPV-prevalence of $54.2 \%$ for hrHPVs, with HPV53, being the most frequently detected type, followed by HPV31, HPV51 and HPV16. Other studies report different order of the most frequent HPVs detected in the anal canal, however, HPVs 16, 53, and 51 have been reported to be in the first five most frequent types [40].

The higher anal HPV-prevalence in individuals with genital HPV-infection has been attributed to selfinoculation. This phenomenon has been shown in men in a sub-analysis of the HIM study reported by Pamnani et al. [41], and it is supported by the quite common finding of the detection of the same HPV types in the anal canal and the genitalia of women and men who have sex with women [11]. The current analysis has shown a statistically significant correlation among the HPV types detected in the anus and the ones detected in the cervix of women referred for colposcopy and this applied to most of the HPV types examined apart from three 
exceptions, namely hr-HPV45, lr-HPV62 and lr-HPV84. However, the limited number of the participants $(n=$ 118) cannot provide the analysis with the power necessary for robust conclusions concerning the interpretation of these associations.

Genital HPV-infection prevalence in women decreases with increasing age [42], and the same phenomenon has been noted concerning anal HPV-detection [40, 43]. We could not demonstrate this decline since the population tested in the current analysis was a referral one. This is the reason that even for cervical HPV-infection, for which the age-related pattern is well established, the highest hr-HPV prevalence was presented by women aged 36-40, and not by women younger than 25. Moreover, anal HPV-detection rate fluctuated, more or less, in a similar way to the cervical one, concerning different age groups, with the exception of two age groups, namely women younger than 25 who presented a cervical hr-HPV-detection rate of $64.3 \%$ and an anal one of $28.6 \%$, and for women $46-50$, for whom the respective values were 30 and $50 \%$ respectively.

In the recent years, there has been significant research on HPV-infection in anatomical sites other than the anogenital area. In particular, there has been an increasing interest in the detection of HPV in the oral cavity and the possible relation of HPV-infection to oropharyngeal cancer. This concerns both sexes but mostly men since this type of cancer is quite more frequent in men than women [44]. However, a systematic review has shown that oral HPV-infection is similar to both sexes, $4.6 \%$ in men and $4.4 \%$ in women [16]. We showed that oral HPV-prevalence was $2.5 \%$ for hr-HPV types in a population at increased risk for HPV-infections. This figure is low compared to the ones reported in the literature for such a population. A meta-analysis on oral HPV-detection rate in women with a cervical HPVinfection yielded a pooled prevalence of $18.1 \%$, and a rate of HPV-type concordance of $27 \%$, which was statistically significant meaning that they found an association between oral and cervical HPV-infection [45]. HPV-type concordance was not documented in our analysis between the cervix or the anus and the oral cavity, however, this is not a robust result since the number of women tested positive for oral HPV was very limited.

\section{Conclusions}

As a conclusion, our results suggest that most HPVtypes, high and low-risk, detected in the cervix of women with prevalent cervical dysplasia, correlate with the ones detected in the anal canal of these women. This particularly applies for the HPV-types related to the nonavalent HPV vaccine (HPVs 6/11/16/18/31/33/45/ 52/58), implying that this vaccine could be used as the "first line of protection", apart from cervical cancer, for anal cancer as well.

\section{Abbreviations}

HPV: Human Papilloma Virus; hr.: High-risk; Ir: Low-risk; MSM: Men who have sex with men; HRA: High-resolution anoscopy; LBC: Liquid-based Cytology; ECC: Endocervical Curettage

\section{Acknowledgements}

We would like to express our gratitude to all the members of the scientific team especially the administrative, medical and laboratory personnel of the involved Medical University Departments of the Aristotle University of Thessaloniki as well as all the women that participated in the study. Finally, we would like to thank the pharmaceutical company AENORASIS S.A. for providing part of the diagnostic kits required for the HPV-DNA detection of the clinical samples.

\section{Authors' contributions}

MN contributed to the conception and design of the study; MN, KC, PDL, EV, NT, GCP, AL, VK, EP and KS to the acquisition (clinical or laboratory), analysis and interpretation of data; $M N, K C, E V, A D, K S$ and $K D$ have drafted the work and substantively revised it. All participating authors have approved the submitted version and have agreed both to be personally accountable for their own contributions and to ensure that questions related to the accuracy or integrity of any part of the work are appropriately investigated, resolved, and the resolution documented in the literature.

\section{Funding}

No funding to report.

Availability of data and materials

All data generated or analyzed during this study are included in this published article.

\section{Compliance with ethical standards}

Ethics approval and consent to participate

All participants provided their written informed consent. The study was approved by the Ethics Committee of Medical Faculty Aristotle University of Thessaloniki (protocol No 125/8.12.2014).

\section{Consent for publication}

Not applicable.

\section{Competing interests}

The authors declare that they have no competing interests.

\section{Author details}

12nd Obstetrics \& Gynaecology Department, Molecular \& Morphological Clinical Cytopathology Laboratory, Hippokration General Hospital, Medical Faculty, School of Health Sciences, Aristotle University of Thessaloniki, Thessaloniki, Greece. ${ }^{2} 1$ st Department of General Surgery, Anal \& Colorectal Clinic, Papageorgiou General Hospital, Medical Faculty, School of Health Sciences, Aristotle University of Thessaloniki, Thessaloniki, Greece.

${ }^{3}$ Stomatology Clinic, School of Dentistry, Aristotle University of Thessaloniki, Thessaloniki, Greece.

Received: 8 November 2019 Accepted: 3 April 2020

Published online: 15 April 2020

\section{References}

1. Walboomers JMM, Jacobs MV, Manos MM, Bosch FX, Kummer JA, Shah KV, et al. Human papillomavirus is a necessary cause of invasive cervical cancer worldwide. J Pathol. 1999;189(1):12-9.

2. Bosch FX, Lorincz A, Muñoz N, Meijer CJLM, Shah KV. The causal relation between human papillomavirus and cervical cancer. J Clin Pathol. 2002;55: 244-65.

3. Burd EM. Human papillomavirus and cervical cancer. Clin Microbiol Rev. 2003;16:1-17.

4. Clarke MA, Wentzensen N. Strategies for screening and early detection of anal cancers: a narrative and systematic review and meta-analysis of 
cytology, HPV testing, and other biomarkers. Cancer Cytopathol. 2018;126: 447-60.

5. Kim SM. Human papilloma virus in oral cancer. J Korean Assoc Oral Maxillofac Surg. 2016;42(6):327.

6. de Sanjosé S, Bruni L, Alemany L. HPV in genital cancers (at the exception of cervical cancer) and anal cancers. Presse Med [lnternet]. 2014 Dec [cited 2019 Oct 22];43(12 Pt 2):e423-8. Available from: http://www.ncbi.nlm.nih. gov/pubmed/25455637.

7. Campisi G, Panzarella V, Giuliani M, Lajolo C, Di Fede O, Falaschini S, et al. Human papillomavirus: its identikit and controversial role in oral oncogenesis, premalignant and malignant lesions (review). Int J Oncol. 2007;30:813-23.

8. Assi R, Reddy V, Einarsdottir H, Longo WE. Anorectal human papillomavirus: current concepts. Yale J Biol Med. 2014;87:537-47.

9. Ruanpeng D, Chariyalertsak S, Kaewpoowat Q, Supindham T, Settakorn J, Sukpan K, et al. Cytological anal squamous intraepithelial lesions associated with anal high-risk human papillomavirus infections among men Who have sex with men in northern Thailand. PLoS ONE [Internet]. 2016 May 1 [cited 2020 mar 20];1 15):e0156280. Available from: http://www.ncbi.nlm.nih.gov/ pubmed/27227684.

10. Giuliano AR, Nyitray AG, Kreimer AR, Pierce Campbell CM, Goodman MT, Sudenga SL, et al. EUROGIN 2014 roadmap: differences in human papillomavirus infection natural history, transmission and human papillomavirus-related cancer incidence by gender and anatomic site of infection. Int J cancer [Internet]. 2015 Jun 15 [cited 2019 Oct 22];136(12): 2752-60. Available from: http://www.ncbi.nlm.nih.gov/pubmed/25043222.

11. Nyitray AG. The epidemiology of anal human papillomavirus infection among women and men having sex with women. Sex Health [Internet]. 2012 Dec [cited 2019 Oct 22];9(6):538-46. Available from: http://www.ncbi. nlm.nih.gov/pubmed/22951119.

12. Stier EA, Sebring MC, Mendez AE, Ba FS, Trimble DD, Chiao EY. Prevalence of anal human papillomavirus infection and anal HPV-related disorders in women: a systematic review. Am J Obstet Gynecol [Internet]. 2015 Sep [cited 2019 Oct 22];213(3):278-309. Available from: http://www.ncbi.nlm.nih. gov/pubmed/25797230.

13. Sichero L, Nyitray AG, Nunes EM, Nepal B, Ferreira S, Sobrinho JS, et al. Diversity of human papillomavirus in the anal canal of men: the HIM study. Clin Microbiol Infect. 2015;21(5):502-9.

14. Kost BP, Hofmann J, Stoellnberger S, Bergauer F, Blankenstein T, AlbaAlejandre I, et al. Prevalence of human papillomavirus infection of the anal canal in women: a prospective analysis of high-risk populations. Oncol Lett. 2017;13(4):2495-501.

15. Candotto V, Lauritano D, Nardone M, Baggi L, Arcuri C, Gatto R, et al. HPV infection in the oral cavity: epidemiology, clinical manifestations and relationship with oral cancer. Oral Implantol (Rome). 2017;10(3):209.

16. Kreimer AR, Bhatia RK, Messeguer AL, González P, Herrero R, Giuliano AR. Oral human papillomavirus in healthy individuals: a systematic review of the literature. Sex Transm Dis. 2010;37:386-91.

17. Syrjänen S, Lodi G, von Bültzingslöwen I, Aliko A, Arduino P, Campisi G, et al. Human papillomaviruses in Oral carcinoma and oral potentially malignant disorders: a systematic review. Oral dis [Internet]. 2011 Apr [cited 2020 mar 20];17(SUPPL. 1):58-72. Available from: http://www.ncbi.nlm.nih. gov/pubmed/21382139.

18. Kaliterna V, Barisic Z. Genital human papillomavirus infections. Front Biosci Landmark [Internet]. 2018 Mar 1 [cited 2020 mar 19];23(9):1587-611. Available from: http://www.ncbi.nlm.nih.gov/pubmed/29293452

19. Saraiya M, Unger ER, Thompson TD, Lynch CF, Hernandez BY, Lyu CW, et al. US assessment of HPV types in cancers: implications for current and 9-valent HPV vaccines. J Natl Cancer Inst [Internet]. 2015 Jun [cited 2020 mar 19];107(6):djv086. Available from: http://www.ncbi.nlm.nih.gov/ pubmed/25925419.

20. Tulay $P$, Serakinci $N$. The role of human papillomaviruses in cancer progression. J Cancer Metastasis Treat. 2016;2(6):201.

21. García-Closas R, Castellsagué X, Bosch X, González CA. The role of diet and nutrition in cervical carcinogenesis: A review of recent evidence. Int J Cancer [Internet]. 2005 Nov 20 [cited 2019 Feb 9];117(4):629-37. Available from: http://doi.wiley.com/10.1002/ijc.21193.

22. Beachler DC, Kreimer AR, Schiffman M, Herrero R, Wacholder S, Rodriguez $A C$, et al. Multisite HPV16/18 vaccine efficacy against cervical, anal, and oral HPV infection. J Nat Cancer Inst [Internet]. 2016 Jan [cited 2019 Oct 22]; 108(1). Available from: http://www.ncbi.nlm.nih.gov/pubmed/26467666.
23. Nayar R, Wilbur D. The Bethesda System for reporting cervical cytology — definitions, criteria, and explanatory notes [Internet]. 3rd ed. In: Nayar R, Wilbur DC, editors. Springer International Publishing; 2015 [cited 2019 Oct 22]. 321 p. Available from: https://www.springer.com/gp/book/ 9783319110738

24. Bornstein J, Bentley J, Bösze P, Girardi F, Haefner H, Menton M, et al. 2011 colposcopic terminology of the International Federation for Cervical Pathology and Colposcopy. Obstet Gynecol [Internet]. 2012 Jul [cited 2019 Oct 22];120(1):166-72. Available from: http://www.ncbi.nlm.nih.gov/ pubmed/22914406.

25. Darragh TM, Colgan TJ, Cox JT, Heller DS, Henry MR, Luff RD, et al. The Lower Anogenital Squamous Terminology Standardization Project for HPVAssociated Lesions: background and consensus recommendations from the College of American Pathologists and the American Society for Colposcopy and Cervical Pathology. Arch Pathol Lab Med [Internet]. 2012 Oct [cited 2019 Oct 22];136(10):1266-97. Available from: http://www.ncbi.nlm.nih.gov/ pubmed/22742517.

26. Albuquerque A. High-resolution anoscopy: unchartered territory for gastroenterologists? World I Gastrointest Endosc [Internet]. 2015 Sep 25 [cited 2019 Oct 22];7(13):1083-7. Available from: http://www.ncbi.nlm.nih. gov/pubmed/26421104.

27. Scully C. Oral and maxillofacial medicine: the basis of diagnosis and treatment: third edition. New York: Elsevier Inc; 2013. p. 1-435.

28. Chatzistamatiou K, Moysiadis T, Vryzas D, Chatzaki E, Kaufmann AM, Koch I, et al. Cigarette smoking promotes infection of cervical cells by high-risk human papillomaviruses, but not subsequent E7 oncoprotein expression. Int J Mol Sci. 2018;1:19(2).

29. Lin DC, Genzen JR. Concordance analysis of paired cancer antigen (CA) 15-3 and 27.29 testing. Breast Cancer Res Treat [Internet]. 2018 [cited 2019 Oct 30];167(1):269-76. Available from: http://www.ncbi.nlm.nih.gov/pubmed/2 8929449.

30. Benevolo M, Donà MG, Ravenda PS, Chiocca S. Anal human papillomavirus infection: prevalence, diagnosis and treatment of related lesions. Expert Rev Anti Infect Ther [Internet]. 2016 [cited 2019 Oct 22];14(5):465-77. Available from: http://www.ncbi.nlm.nih.gov/pubmed/27050294.

31. Watson M, Saraiya M, Ahmed F, Cardinez CJ, Reichman ME, Weir HK, et al. Using population-based cancer registry data to assess the burden of human papillomavirus-associated cancers in the United States: overview of methods. Cancer [Internet]. 2008 Nov 15 [cited 2019 Oct 22];113(10 Suppl): 2841-54. Available from: http://www.ncbi.n/m.nih.gov/pubmed/18980203.

32. De Martel C, Ferlay J, Franceschi S, Vignat J, Bray F, Forman D, et al. Global burden of cancers attributable to infections in 2008: a review and synthetic analysis. Lancet Oncol. 2012;13(6):607-15.

33. Siegel RL, Miller KD, Jemal A. Cancer statistics, 2020. CA Cancer J Clin [Internet]. 2020 Jan 8 [cited 2020 Mar 20];70(1):7-30. Available from: https:// onlinelibrary.wiley.com/doi/abs/10.3322/caac.21590.

34. Sehnal B, Dusek L, Cibula D, Zima T, Halaska M, Driak D, et al. The relationship between the cervical and anal HPV infection in women with cervical intraepithelial neoplasia. J Clin Virol [Internet]. 2014 Jan [cited 2019 Oct 22];59(1):18-23. Available from: http://www.ncbi.nlm.nih.gov/ pubmed/24315797.

35. Véo CAR, Saad SS, Nicolau SM, Melani AGF, Denadai MVA. Study on the prevalence of human papillomavirus in the anal canal of women with cervical intraepithelial neoplasia grade III. Eur J Obstet Gynecol Reprod Biol [Internet]. 2008 Sep [cited 2019 Oct 22];140(1):103-7. Available from: http:// www.ncbi.nlm.nih.gov/pubmed/18472205.

36. Ebisch RMF, Rutten DWE, IntHout J, Melchers WJG, Massuger LFAG, Bulten J, et al. Long-lasting increased risk of human papillomavirus-related carcinomas and premalignancies after cervical intraepithelial neoplasia grade 3: a population-based cohort study. J Clin Oncol [Internet]. 2017 Aug 1 [cited 2020 mar 20];35(22):2542-50. Available from: http://www.ncbi.nlm. nih.gov/pubmed/28541790.

37. Teng CJ, Huon LK, Hu YW, Yeh CM, Chao Y, Yang MH, et al. Secondary primary malignancy risk in patients with cervical cancer in Taiwan: A nationwide population-based study. Med (United States) [Internet]. 2015 Oct [cited 2020 mar 20];94(43):e1803. Available from: http://www.ncbi.nlm. nih.gov/pubmed/26512575.

38. Acevedo-Fontánez Al, Suárez E, Torres Cintrón CR, Ortiz AP. Risk of anal cancer in women with a human papillomavirus-related gynecological neoplasm: Puerto Rico 1987-2013 [Internet]. Vol. 22, Journal of Lower Genital Tract Disease. Lippincott Williams and Wilkins; 2018 [cited 2020 
Mar 20]. p. 225-30. Available from: http://www.ncbi.nlm.nih.gov/ pubmed/29649025.

39. Tomassi MJ, Abbas MA, Klaristenfeld DD. Expectant management surveillance for patients at risk for invasive squamous cell carcinoma of the anus: a large US healthcare system experience. Int J Colorectal Dis [Internet]. 2019 Jan 31 [cited 2020 mar 20];34(1):47-54. Available from: http://www. ncbi.nlm.nih.gov/pubmed/30244347.

40. Hernandez BY, McDuffie K, Zhu X, Wilkens LR, Killeen J, Kessel B, et al. Anal human papillomavirus infection in women and its relationship with cervical infection. Cancer Epidemiol Biomarkers Prev [Internet]. 2005 Nov [cited 2019 Oct 22];14(11 Pt 1):2550-6. Available from: http://www.ncbi.nlm.nih.gov/ pubmed/16284377.

41. Pamnani SJ, Nyitray AG, Abrahamsen M, Rollison DE, Villa LL, Lazcano-Ponce

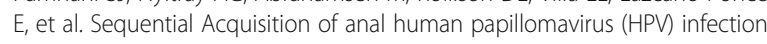
following genital infection among men who have sex with women: the HPV Infection in Men (HIM) study. J Infect Dis [Internet]. 2016 [cited 2019 Oct 22];214(8):1180-7. Available from: http://www.ncbi.nlm.nih.gov/ pubmed/27489298.

42. Poynten IM, Machalek D, Templeton D, Jin F, Hillman R, Zablotzska I, et al. Comparison of age-specific patterns of sexual behaviour and anal HPV prevalence in homosexual men with patterns in women. Sex Transm Infect [Internet]. 2016 May [cited 2019 Oct 22];92(3):228-31. Available from: http:// www.ncbi.nlm.nih.gov/pubmed/26306829.

43. Hernandez BY, Ka'Opua LS, Scanlan L, Ching JA, Kamemoto LE, Thompson PJ, et al. Cervical and anal human papillomavirus infection in adult women in American Samoa. Asia Pac J Public Health. 2013;25(1):19-31.

44. Gillison ML, Castellsagué X, Chaturvedi A, Goodman MT, Snijders P, Tommasino M, et al. Eurogin Roadmap: comparative epidemiology of HPV infection and associated cancers of the head and neck and cervix. Int J Cancer [Internet]. 2014 Feb 1 [cited 2019 Oct 22];134(3):497-507. Available from: http://www.ncbi.nlm.nih.gov/pubmed/23568556.

45. Termine N, Giovannelli L, Matranga D, Caleca MP, Bellavia C, Perino A, et al. Oral human papillomavirus infection in women with cervical HPV infection: new data from an Italian cohort and a metanalysis of the literature. Oral Oncol [Internet]. 2011 Apr [cited 2019 Oct 22];47(4):244-50. Available from: http://www.ncbi.nlm.nih.gov/pubmed/21429788.

\section{Publisher's Note}

Springer Nature remains neutral with regard to jurisdictional claims in published maps and institutional affiliations.

Ready to submit your research? Choose BMC and benefit from:

- fast, convenient online submission

- thorough peer review by experienced researchers in your field

- rapid publication on acceptance

- support for research data, including large and complex data types

- gold Open Access which fosters wider collaboration and increased citations

- maximum visibility for your research: over $100 \mathrm{M}$ website views per year

At $\mathrm{BMC}$, research is always in progress.

Learn more biomedcentral.com/submissions 